\title{
PENGARUH HARAPAN TERHADAP RESILIENSI WANITA DEWASA MUDA YANG PERNAH MENGALAMI ABORTUS SPONTAN
}

\author{
Cintya Amelia Cathlin', Yuliana Anggreany, \& Wiwit Puspitasari Dewi \\ Fakultas Psikologi, Universitas Pelita Harapan, Jl. MH. Thamrin Boulevard 1100, Lippo Karawaci, Jakarta \\ 15811, Indonesia
}

Korespondensi:

${ }^{1}$ e-mail: cintyamelia.17@gmail.com

\begin{abstract}
A child presence is a waited moment for young married couples. Unfortunately, some couples have difficulties for having a child. One of the reasons is because of miscarriage or spontaneous abortion. Spontaneous abortion can cause stress to young adult women. They need hope as a protective factor to remain resilient in overcoming stress and to function like before. Thepurpose of this study is to examine the effect of hope on young adult women resilience with spontaneous abortion. The regression models were developed using cross-sectional data. Fifty six participants were recruited through purposive sampling method from Jakarta, Bogor, Depok, Tangerang, and Bekasi. Result showed that hope affects 18.9 percent on resilience of young adult women with spontaneous abortion. The study demonstrated that there is a significant effect of hope on resilience among young adult women with spontaneous abortion.
\end{abstract} Article history:

Received 12 October 2017

Received in revised form 26 March 2018

Accepted 29 October 2018

Available online 1 March 2019

\begin{abstract}
Abstrak - Kehadiran anak menjadi salah satu hal yang dinantikan pasangan muda yang baru menikah. Namun, sejumlah pasangan harus berjuang untuk mendapatkan anak. Salah satu penyebab sulitnya wanita dewasa muda dalam memiliki anak adalah keguguran atau abortus spontan. Kejadian abortus spontan dapat meninggalkan dampak yang membuat wanita dewasa muda masuk dalam kondisi stres. Oleh karena itu, dibutuhkan harapan sebagai faktor protektif resiliensi agar mereka dapat keluar dari kondisi stres dan berfungsi seperti sedia kala. Penelitian ini bertujuan untuk melihat pengaruh harapan terhadap resiliensi wanita dewasa muda yang pernah mengalami abortus spontan. Metode penelitian yang digunakan adalah penelitian kuantitatif regresi melalui data cross-sectional. Sebanyak 56 partisipan diperoleh melalui teknik purposive sampling dengan lingkup geografis di daerah Jakarta, Bogor, Depok, Tangerang, dan Bekasi. Hasil penelitian menunjukkan bahwa sebesar 18.9 persen harapan memengaruhi resiliensi wanita dewasa muda yang pernah mengalami abortus spontan. Studi ini menunjukkan terdapat pengaruh harapan yang signifikan pada resiliensi wanita dewasa muda yang pernah mengalami abortus spontan.
\end{abstract}

Kata Kunci: harapan; resiliensi; abortus spontan; wanita dewasa muda 


\section{PENDAHULUAN}

Dewasa muda yang memiliki rentang usia 20 hingga 40 tahun sedang berada pada tahap perkembangan psikososial intimasi versus isolasi (intimacy versus isolation) (Erikson, dalam Santrock, 2012). Pada masa ini, seorang dewasa muda akan membentuk hubungan yang intim dengan pasangannya dan mewujudkannya melalui komitmen menuju hubungan pernikahan (Agusdwitanti, Tambunan, \& Retnaningsih, 2015). Hurlock (dalam Khairani \& Putri, 2008) menyatakan bahwa dewasa muda dapat membentuk keluarga, membesarkan anak-anak, dan mengelola rumah tangga melalui hubungan pernikahan yang dijalani. Dengan demikian, merupakan hal umum apabila seorang dewasa muda menjalani pernikahan dan memiliki anak.

Kehadiran anak menjadi salah satu hal yang dinantikan oleh pasangan muda yang baru menikah. Namun, sejumlah wanita dewasa muda tidak jarang menghadapi kesulitan saat mengandung. Salah satu masalah kehamilan yang terjadi adalah keguguran atau abortus spontan. Data Riset Kesehatan Dasar 2010 (Badan Litbang Kesehatan, dalam Pranata \& Sadewo, 2012) menyatakan bahwa Papua Barat menempati posisi tertinggi kejadian abortus spontan dengan persentase 6.9 persen dan Bengkulu menempati posisi terendah dengan persentase 2.4 persen. Anshor (dalam Habi, Kasim, \& Pakaya, 2015) menyatakan bahwa 10-15 persen atau sekitar 600900 ribu kasus abortus spontan terjadi dari enam juta kehamilan di Indonesia setiap tahunnya.

Abortus spontan merupakan penghentian masa kehamilan yang terjadi sebelum mencapai usia 20 minggu atau saat janin memiliki berat kurang dari 500 gram (Prawihardjo, dalam Mardiyanti, 2015; National Center for Health Statistics, the Centers for Disease Control and Prevention, \& World Health Organization, dalam Cunningham dkk., 2014). Faktor-faktor yang menyebabkan terjadinya abortus spontan adalah faktor ibu (maternal) (Prawirohardjo, dalam Junita 2013) dan faktor janin (Mardiyanti, 2015; Farrer, dalam Darmawati, 2011).

Kejadian abortus spontan ini dapat menimbulkan dampak fisik dan psikologis yang membekas dalam kehidupan seseorang (Clowes, dalam Saifullah, 2011). Dampak fisik yang dialami dapat berupa pendarahan dalam vagina, kram perut, dan suhu badan meningkat (Cunningham dkk., 2014). Dampak psikologis yang dialami dapat berupa dukacita (suffer from grief), merasa bersalah, depresi, dan cemas akibat kehilangan bayinya (Broen, Moum, Bodtker, \& Ekeberg, 2004). Lentz, Lobo, Gershenson, dan Katz (2012) menyatakan bahwa tingkat depresi dan rasa bersalah meningkat tajam pada wanita yang baru saja mengalami abortus spontan. American College of Obstetricians and Gynecologists [ACOG] (dalam Dell, 2002) menyatakan wanita yang 
baru saja mengalami abortus spontan memiliki tingkat depresi dan kecemasan yang tinggi dibandingkan dengan wanita yang berhasil melahirkan anaknya dalam kurun waktu enam bulan pertama setelah abortus spontan terjadi. Dampak psikologis tersebut timbul sebagai bentuk dukacita (grief) wanita yang mengalami abortus. Dukacita akibat abortus spontan ini juga memiliki intensitas yang sama seperti kehilangan lain dalam hidup seseorang (Dell, 2002).

Dampak fisik maupun psikologis yang dialami wanita dewasa muda yang mengalami abortus spontan menyebabkan mereka masuk ke dalam kondisi penuh stres sehingga terganggu fungsinya. Kehidupan yang terus berjalan membuat mereka harus keluar dari kondisi penuh stres dengan dorongan dan jalan yang muncul dari dalam diri. Dorongan dan jalan ini terdapat di dalam harapan (Snyder, 1994). Harapan pada wanita dewasa muda membantu mereka meningkatkan kemampuan untuk bertahan hingga kembali pulih menuju fungsi hidupnya seperti sedia kala. Kemampuan untuk bertahan hingga dapat kembali pulih ini disebut resiliensi (Wright, Masten, \& Narayan, 2013). Penelitian Jansen dkk. (dalam Dell, 2002) menunjukkan bahwa kebanyakan wanita yang pernah mengalami abortus spontan dapat kembali ke garis dasar (baseline) mereka setelah satu tahun mengalami abortus spontan. Hal ini ditandai dengan kembali beraktivitas sehari-hari dan memulai mengintegrasikan kehilangan mereka. Oleh karena itu, harapan yang dimiliki wanita dewasa muda dapat membantu mereka meningkatkan resiliensi agar dapat kembali ke garis dasar setelah mengalami abortus spontan.

\section{Harapan}

Wanita dewasa muda membutuhkan dorongan dan jalan untuk dapat keluar dari kondisi penuh stres di dalam proses untuk kembali menuju garis dasar. Dorongan dan jalan ini terdapat di dalam harapan (hope) yang mencakup gabungan antara mental willpower dan waypower yang untuk mencapai tujuan (Snyder, 1994). Willpower adalah keinginan, motivasi, tekad, dan hal-hal yang seseorang butuhkan untuk membuatnya bergerak mencapai tujuan, sedangkan waypower adalah rencana mental yang memberi arahan pada seseorang untuk menemukan cara efektif, strategi, baik satu ataupun lebih, untuk mencapai tujuan yang telah ditetapkan seseorang (Snyder, 1994).

Snyder (1994) menyatakan bahwa tingkat harapan individu berbeda-beda bergantung pada kapasitas willpower dan waypower yang dimiliki, begitu juga dengan harapan pada wanita dewasa muda. Individu yang memiliki tingkat harapan rendah dicirikan dengan tingkat willpower dan waypower yang rendah. Biasanya mereka akan merasa tidak mampu untuk mencapai tujuan yang 
diinginkan dan banyak dipenuhi oleh emosi negatif. Individu dengan harapan rendah juga dilaporkan merasa lebih kesepian (Arieti \& Arieti, dalam Snyder, 1994). Individu ini akan mengalami kesulitan mempertahankan pemikiran penuh harapan di masa dewasanya. Mereka juga akan kesulitan untuk mengungkapkan masalah yang dialami sehingga dapat menyebabkan kondisi psikologis mereka bermasalah dan tidak dapat melewati permasalahan yang dihadapi. Sebaliknya, individu yang memiliki tingkat harapan tinggi dicirikan dengan tingkat willpower dan waypower yang tinggi. Biasanya, mereka memiliki tujuan yang jelas dalam pikirannya, selalu berpikir untuk meraihnya berulang kali, selalu percaya bahwa banyak pilihan tersedia untuk meraih tujuannya, dan fleksibel dalam menentukan ide-ide yang dapat memfasilitasi dirinya meraih tujuan. Karakteristik harapan yang tinggi ini menjadi penentu untuk dapat melewati kondisi yang tidak menguntungkan bagi individu (Snyder, dalam Kim, Lee, Yu, Lee, \& Puig, 2005).

\section{Resiliensi}

Resiliensi didefinisikan sebagai sebuah kapasitas atas sistem dinamis bagi seseorang untuk dapat bertahan atau kembali pulih dari kekacauan (disturbance) (Wright dkk., 2013). Ketika wanita dewasa muda berada dalam kondisi stres atau sulit akibat kehilangan jabang bayinya, resiliensi memampukannya untuk bangkit kembali (Kirmani, Sharma, Anas, \& Sanam, 2015; Malik, 2013; Shetty, 2015) dan bahkan mereka dapat berfungsi lebih baik daripada sebelum berada dalam situasi stres (Shetty, 2015).

Resiliensi memiliki empat fungsi, yaitu overcoming, steering through, bounce back, dan reaching out (Reivich \& Shatté, 2002). Ketika wanita dewasa muda kehilangan jabang bayinya, resiliensi dibutuhkan agar individu mampu menghadapi (overcoming) permasalahan yang menimpanya. Individu yang resilien menggunakan kemampuan yang dia miliki untuk dapat melewati permasalahannya (steering through) tanpa harus merasa kewalahan dan berespon negatif atas kejadian yang menimpanya. Resiliensi juga membuat wanita dewasa muda menggunakan koneksi dalam lingkungannya sehingga ia dapat bangkit dan melewati masa traumanya (bounce back). Fungsi terakhir, yakni reaching out membuat wanita dewasa muda mampu menilai risiko yang akan terjadi, memahami dirinya dengan baik, dan mampu menemukan tujuan serta makna hidupnya. Fungsi-fungsi ini pada akhirnya akan membawa wanita dewasa muda bangkit, keluar, dan berhasil melewati masa berdukanya sehingga dapat menjalani kehidupan seperti sedia kala atau lebih baik daripada sebelum mengalami abortus spontan. 


\section{Pengaruh Harapan Terhadap Resiliensi}

Resiliensi memiliki faktor-faktor protektif yang dapat mengurangi atau menghilangkan efek dari situasi sulit yang dihadapi individu (Masten, dalam Karatas \& Cakar, 2011). Faktor-faktor tersebut, antara lain: regulasi emosi, dukungan sosial, pola asuh, spiritualitas, dan harapan. Harapan menjadi faktor protektif resiliensi terpenting (Bailey \& Snyder, dalam Shetty, 2015; Garnefski dkk., dalam Hochhalter, Smith, \& Ory, 2011) karena harapan akan tetap ada dalam diri ketika individu berada dalam keadaan yang mengancam nyawanya (Snyder, dalam Duggal, Zimmerman, \& Liberta, 2016). Meskipun banyak hambatan dan tantangan, harapan memampukan individu untuk berfungsi secara efektif (Snyder, dalam Mednick dkk.,2007).

Willpower menimbulkan dorongan bagi individu untuk dapat menghadapi kesulitan yang sedang dihadapi dan membuat individu bertekad untuk menuntun dirinya keluar dari kondisi stres (Snyder, 1994). Willpower membuat individu terus-menerus memikirkan dan menyakinkan dirinya bahwa kondisi stres yang dialaminya dapat terlewati. Tekad dan keyakinan yang timbul membuat individu mampu untuk mencegah kondisi stres menguasai dirinya. Willpower bekerja bersama-sama dengan waypower dalam membuat individu memikirkan cara atau strategi terbaik dan paling efektif untuk keluar dari kondisi stres (Snyder, 1994). Pemikiran ini menjadikan individu fleksibel dan bertindak aktif dalam usahanya untuk keluar dari kondisi stres sehingga pemikirannya fokus ke masa depan dan individu dapat dengan mudah mengantisipasi masalah yang mungkin datang (Snyder, dalam Oktan, 2012).

Tujuan penelitian ini adalah mengetahui secara empiris pengaruh harapan terhadap resiliensi wanita dewasa muda yang pernah mengalami abortus spontan. Oleh karena itu, penelitian ini ingin membuktikan sebuah hipotesis, yaitu ada atau tidaknya pengaruh harapan terhadap resiliensi pada wanita dewasa muda yang pernah mengalami abortus spontan.

\section{METODE}

\section{Partisipan}

Teknik pengambilan sampel penelitian menggunakan teknik pengambilan sampel secara sengaja (purposive sampling) karena dibutuhkan karakteristik tertentu yang telah ditentukan dalam penelitian (Sugiyono, 2012). Sampel yang digunakan berjumlah 56 orang wanita dewasa muda dengan rentang usia 20-40 tahun dan bertempat tinggal di Jakarta, Bogor, Depok, Tangerang, dan Bekasi. Karakteristik partisipan lainnya pada penelitian ini adalah wanita dewasa muda yang pernah 
mengalami abortus spontan dengan usia janin 0-20 minggu dan telah mengalami abortus spontan dengan waktu lebih dari satu tahun (Janssen, dalam Dell, 2002).

\section{Desain}

Desain penelitian yang digunakan untuk penelitian kuantitatif regresi ini menggunakan pendekatan cross-sectional. Cross-sectional adalah jenis pengambilan data yang dilakukan satu kali dalam satu waktu tanpa memanipulasi variabel yang diteliti (Gravetter \& Forzano, 2012). Jenis penelitian uji regresi ini dilakukan untuk menguji pengaruh variabel bebas, yaitu harapan terhadap variabel terikat, yaitu resiliensi.

\section{Prosedur}

Alat ukur yang digunakan adalah Adult Dispositional (Trait) Hope Scale dengan total 12 butir multidimensional (Snyder, 1994) dan Brief Resilience Scale dengan total enam butir unidimensional (Smith dkk., 2008) yang sudah valid dan reliabel. Alat ukur berupa kuesioner disebarkan, baik dalam bentuk cetak, maupun online melalui akun media sosial seperti Line, Instagram, Facebook, dan laman web ibuhamil.com.

Berikut adalah hasil validitas dan reliabilitas kedua alat ukur penelitian ini.

Tabel 1.

Informasi Psikometri Alat Ukur

\begin{tabular}{cc}
\hline Konstruk & Reliabilitas \\
\hline Harapan & $\mathbf{. 7 4 8}$ \\
Niat & .557 \\
Akses & .677 \\
Resiliensi & $\mathbf{. 7 5 2}$ \\
\hline
\end{tabular}

Keterangan: Konstruk yang dicetak tebal merupakan konstruk utama.

\section{Teknik Analisis}

Pengolahan data yang dilakukan pada penelitian ini adalah uji asumsi klasik yang terdiri dari uji normalitas data yang diuji dengan metode Kolmogorov-Smirnov test, uji linieritas, dan uji heteroskedastisitas. Selain itu, dilakukan juga uji reliabilitas dengan menggunakan Cronbach Alpha dan melihat corrected item-total correlation pada partisipan penelitian. 


\section{ANALISIS DAN HASIL}

Hasil uji korelasi Pearson antara harapan dan resiliensi menghasilkan korelasi positif signifikan $\left(r_{s}=.435, p=.001\right)$, maka data dapat digunakan untuk melakukan uji regresi linear. Analisis terhadap pengaruh variabel bebas, yaitu harapan, terhadap variabel terikat, yaitu resiliensi, pada 56 orang wanita dewasa muda yang pernah mengalami abortus spontan di Jakarta, Bogor, Depok, Tangerang, dan Bekasi menunjukkan adanya pengaruh yang signifikan $\left(R^{2}=.189, t=\right.$ $3.546, F=12.576, p=.001)$.

Peneliti juga melakukan uji korelasi antara setiap dimensi harapan dengan resiliensi. Dimensi pertama harapan, yaitu willpower dan resiliensi memiliki korelasi positif signifikan $(r=$ $.512, p=.000)$. Koefisien korelasi ini memiliki tingkat korelasi sedang karena berada di rentang 0.4 hingga 0.59 (Nisfiannoor, 2009). Dimensi kedua harapan, yaitu waypower memiliki korelasi positif signifikan dengan resiliensi $(r=0.289 ; p=.000)$. Koefisien korelasi ini memiliki tingkat korelasi rendah karena berada di rentang .2 hingga .39 (Nisfiannoor, 2009).

\section{DISKUSI}

Penelitian ini bertujuan untuk mengetahui pengaruh harapan terhadap resiliensi wanita dewasa muda yang pernah mengalami abortus spontan. Hasil menunjukkan bahwa harapan mempunyai pengaruh sebesar 18.9 persen terhadap resiliensi, sedangkan sisanya sebesar 81.1 persen dipengaruhi oleh variabel atau faktor lain yang tidak diukur dalam penelitian ini. Jadi, hipotesis akhir penelitian ini diterima, yaitu terdapat pengaruh harapan yang signifikan terhadap resiliensi wanita dewasa muda yang pernah mengalami abortus spontan.

Hasil yang didapat ini sejalan dengan teori yang ada bahwa harapan sebagai faktor protektif resiliensi (Bailey \& Snyder, dalam Shetty, 2015; Garnefski dkk., dalam Hochhalter, Smith, \& Ory, 2011) berfungsi untuk mengurangi atau menghilangkan efek dari kondisi stres yang dihadapi wanita dewasa muda yang pernah mengalami abortus spontan. Harapan berperan sebagai pelindung untuk masalah yang terjadi secara tidak terduga, yaitu abortus spontan. Pengalaman abortus spontan yang telah terjadi di masa lalu membuat wanita dewasa muda dengan harapan tinggi mampu meminimalkan dampak negatif yang mungkin terjadi akibat abortus spontan. Snyder (1994) menyatakan bahwa individu dengan harapan tinggi memiliki tingkat depresi dan luka (impairment) 
yang lebih rendah dibandingkan dengan individu dengan harapan rendah dalam menghadapi cedera traumatik. Harapan membuat wanita dewasa muda dapat bertahan menghadapi cedera traumatik yang mereka hadapi sebagai dampak fisik maupun psikologis dari abortus spontan.

Kemampuan untuk bertahan menghadapi cedera traumatik ini dinamakan sebagai resiliensi. Ketika resiliensi diperkuat oleh faktor protektif resiliensi, wanita dewasa muda mampu menilai risiko yang akan terjadi, memahami dirinya dengan baik, dan mampu menemukan tujuan serta makna hidupnya (Reivich \& Shatte, 2002). Penguatan faktor protektif resiliensi ini membuat mereka dapat bangkit dan mencapai garis dasar mereka sebagai akibat abortus spontan.

Peneliti juga melakukan uji korelasi antara setiap dimensi harapan dengan resiliensi. Willpower diketahui berkorelasi positif dengan resiliensi, artinya ketika willpower di dalam diri wanita dewasa muda yang pernah mengalami abortus spontan tinggi, maka resiliensinya juga akan tinggi, begitu juga sebaliknya. Hal ini sejalan dengan teori yang menyatakan bahwa willpower dapat membuat wanita dewasa muda memiliki tekad kuat dari dalam diri yang menuntunnya keluar dari kondisi sulit setelah mengalami abortus spontan. Keinginan dan tekad yang kuat mendorong wanita dewasa muda untuk memulai dan mempertahankan aksinya. Hal ini ditunjukkan dengan salah satu karakteristik wanita dewasa muda dengan willpower tinggi di mana mereka lebih optimis dan memiliki kontrol (perceptions of control over one's life) dalam menghadapi kondisi stres (Snyder, 1994). Keadaan tersebut membuat wanita dewasa muda mampu menyakinkan dirinya bahwa kondisi stres yang dialami menjadi suatu batu loncatan dalam hidupnya. Willpower akan membuat wanita dewasa muda mampu memecahkan masalah (steering through) tanpa harus merasa kewalahan dan bertindak negatif atas kondisi stres yang menimpanya (Reivich \& Shatte, 2002). Kemampuan untuk memecahkan masalah tanpa harus merasa kewalahan dan bertindak negatif atas kondisi stres ini dinamakan sebagai resiliensi.

Dimensi kedua harapan, yaitu waypower, juga berkorelasi positif signifikan dengan resiliensi, yang berarti ketika waypower di dalam diri wanita dewasa muda yang pernah mengalami abortus spontan tinggi, maka resiliensinya juga akan tinggi, begitu juga sebaliknya. Hal ini sejalan dengan teori yang mengatakan bahwa waypower membuat wanita dewasa muda dipenuhi banyak strategi di dalam pikirannya sehingga individu dapat menemukan banyak jalan dan memiliki pemikiran yang fleksibel untuk dapat keluar dari kondisi sulit (Snyder, 1994). Wanita dewasa muda dengan waypower tinggi tidak akan berhenti apabila mereka menemukan hambatan di jalan yang telah mereka pilih untuk mencapai tujuan-tujuan. Mereka justru akan mencari jalan alternatif dalam menanggulangi hambatan yang terjadi. Karakteristik ini dinamakan sebagai kemampuan 
memecahkan masalah (perceived problem-solving ability) yang kemudian membuat wanita dewasa muda bangkit dan melewati masa traumanya. Proses untuk dapat bangkit dan melewati masa traumanya terdapat di dalam resiliensi.

Salah satu cara yang dilakukan wanita dewasa muda untuk dapat mewujudkan fungsi resiliensi adalah membentuk koneksi dalam lingkungannya untuk bangkit dan melewati masa trauma serta menggunakan koneksi tersebut sebagai sumber untuk mencapai apa yang diinginkannya (Reivich \& Shatte, 2002). Dalam hal ini, harapan membantu wanita dewasa muda yang berada dalam kondisi stres akibat abortus spontan untuk mencari orang-orang terdekat yang berpotensi menjadi pendukung mereka (Snyder, 1994). Relasi yang dimiliki membantu wanita dewasa muda untuk mendiskusikan tujuan-tujuan yang ingin dicapai dan masalah yang dihadapi dalam mencapai tujuan-tujuan tersebut.

Berdasarkan data penelitian, didapatkan bahwa suami (89.3\%) menjadi sumber dukungan sosial yang paling banyak dipilih partisipan. Hal ini sejalan dengan tahap perkembangan psikososial Erikson (dalam Papalia, Feldman, \& Martorell, 2012) bahwa wanita dewasa muda membentuk hubungan yang intim, yaitu melalui pernikahan. Suami menjadi pasangan yang diharapkan wanita dewasa muda untuk dapat membangun keluarga bersama (Hurlock, dalam Khairani, \& Putri, 2008). Setelah menikah, wanita dewasa muda akan pergi meninggalkan orang tuanya sehingga satusatunya orang yang dekat dengan wanita dewasa muda saat abortus spontan terjadi adalah suami. Selain suami, Tuhan (69.6\%) dan orang tua $(64.3 \%)$ juga menjadi sumber dukungan terbanyak kedua dan ketiga yang dipilih partisipan. Berkat dukungan sosial yang dapat diakses oleh wanita dewasa muda membuat mereka mendapatkan kekuatan sehingga mereka mampu untuk menghadapi kehidupannya di masa depan (Ayu, 2012).

Meskipun begitu, hal ini tidak didukung dengan adanya korelasi signifikan yang dilakukan pada variabel resiliensi dengan banyaknya dukungan sosial yang didapat pada penelitian ini. Peneliti melakukan uji korelasi dengan menjumlahkan total sumber dukungan sosial yang didapatkan setiap partisipan lalu mengaitkannya dengan resiliensi. Hal ini mengindikasikan bahwa banyaknya sumber dukungan sosial yang didapat partisipan tidak menjadi faktor utama dalam meningkatkan kemampuan untuk bangkit dari kondisi stres, namun lebih kepada cara partisipan memanfaatkan dukungan sosial untuk memperoleh bantuan emosional (Cohen \& Wills, dalam Smith, Tooley, Christopher, \& Kay, 2010).

Berdasarkan data penelitian ini, didapatkan bahwa kebanyakan variasi dampak abortus spontan yang dialami oleh partisipan adalah merasa bersalah (51.8\%), terkejut (shock) (46.4\%), dan 
tidak dapat menahan rasa tangis (46.4\%). Hal ini menunjukkan bahwa banyak dampak psikologis yang dirasakan wanita dewasa muda yang mengalami abortus spontan. Meskipun begitu, hal ini menjadi keterbatasan dalam penelitian ini karena proporsi yang tidak sesuai antara dampak fisik dan dampak psikologis yang dipaparkan peneliti dalam pilihan kuesioner. Akibatnya, peneliti tidak dapat menyimpulkan jumlah dampak yang lebih banyak dirasakan oleh partisipan.

Penelitian ini tidak terlepas dari keterbatasan yang dibuat oleh peneliti dalam proses menyelesaikan penelitian ini. Peneliti menyadari bahwa individu dengan harapan pasti memiliki tujuan-tujuan yang akan dicapai. Namun, peneliti tidak menanyakan tujuan-tujuan tersebut kepada partisipan dalam kuesioner penelitian. Hal ini menyebabkan peneliti tidak dapat mengetahui secara pasti tujuan-tujuan yang ingin dicapai setelah partisipan mengalami abortus spontan. Keterbatasan lainnya adalah proporsi partisipan yang tidak seimbang untuk beberapa analisis data tambahan, seperti pada data demografis agama, pendidikan, suku, dan jumlah anak partisipan sehingga menyebabkan keakuratan data yang telah diuji perlu diuji kembali pada penelitian selanjutnya.

\section{SIMPULAN DAN SARAN}

\section{Simpulan}

Kesimpulan yang didapat dari penelitian ini adalah terdapat pengaruh harapan yang signifikan terhadap resiliensi wanita dewasa muda yang pernah mengalami abortus spontan. Hasil analisis korelasi dimensi harapan memiliki korelasi yang positif signifikan dengan resiliensi wanita dewasa muda yang pernah mengalami abortus spontan. Hal ini berarti semakin tinggi dimensi harapan, maka semakin tinggi juga resiliensi yang dimiliki. Dimensi pertama harapan, yaitu willpower dan resiliensi memiliki korelasi positif signifikan. Dimensi kedua harapan, yaitu waypower memiliki korelasi positif signifikan dengan resiliensi.

\section{Saran Teoretis}

Saran teoretis yang dapat diberikan untuk penelitian selanjutnya yang serupa adalah dapat dilakukannya penelitian lebih lanjut terkait faktor atau variabel lain yang berperan dalam memengaruhi resiliensi wanita dewasa muda yang pernah mengalami abortus spontan dan memperluas sampel penelitian agar data yang didapat lebih bervariatif. Kontrol lain yang perlu diperhitungkan pada penelitian selanjutnya adalah jangka waktu pernikahan pasangan sebelum 
mengalami abortus spontan, jumlah anak yang dimiliki sebelum mengalami abortus spontan, baik itu sudah memiliki anak atau belum, dan urutan kelahiran anak saat mengalami abortus spontan.

\section{Saran Praktis}

Hasil penelitian ini diharapkan dapat menjadi sumber informasi bagi wanita dewasa muda yang pernah mengalami abortus spontan dalam meningkatkan harapan yang dimilikinya. Praktisi kesehatan mental yang menangani kasus relevan dapat berfokus pada penguatan sumber dukungan sosial pada wanita dewasa muda yang pernah mengalami abortus spontan. Institusi maupun praktisi dapat mencanangkan program intervensi, baik dalam bentuk seminar, penyuluhan, maupun edukasi yang berfokus pada pentingnya harapan dan upaya meningkatkan harapan untuk membentuk resiliensi wanita dewasa muda yang pernah mengalami abortus spontan.

\section{REFERENSI}

Agusdwitanti, H., Tambunan, S. M., \& Retnaningsih. (2015). Kelekatan dan intimasi pada dewasa awal. Jurnal Psikologi, 8(1), 18-24.

Ayu, I. B. (2012). Resiliensi pada wanita yang mengalami abortus spontanea. Jurnal Penelitian dan Pengukuran Psikologi, 1(1), 71-77.

Broen, A. N., Moum, T., Bodtker, A. S., \& Ekeberg, O. (2004). Psychological impact on women of miscarriage versus induced abortion: a 2-year follow-up study. Psychosomatic Medicine, 66, 265-271.

Cunningham F. G., Leveno, K. J., Bloom, S. L., Spong, C. Y., Dashe, J. S., Hoffman, B. L., Casey, B. M., \& Sheffield, J. S. (2014). Williams obstetrics (24th ed.). New York, NY: McGrawHill.

Darmawati. (2011). Mengenali abortus dan faktor yang berhubungan dengan kejadian abortus. Idea Nursing Journal, 2(1), 12-18.

Dell, D. L. (2002). Gynecology. In S. G. Kornstein, \& A. H. Clayton, Women's mental health (hlm. 361-362). New York, NY: The Guilford Press.

Duggal, D., Zimmerman, A. S., \& Liberta, T. (2016). The impact of hope and resilience on multiple factors in neurosurgical patients. Cureus, 8(10), 1-7. doi: 10.7759/cureus.849

Gravetter, F. J., \& Forzano, L. A. B. (2012). Research methods for the behavioral sciences (4th ed.). Belmont, CA: Wadsworth Cengage Learning. 
Habi, V. S., Kasim, V. N., \& Pakaya, A. W. (2015). Faktor-faktor yang mempengaruhi terjadinya abortus pada ibu hamil di wilayah kerja puskesmas di Kabupaten Gorontalo Utara. Jurusan Keperawatan Fakultas Ilmu-Ilmu Kesehatan dan Keolahragaan Universitas Negeri Gorontalo, 69-76.

Hochhalter, A. K., Smith, M. L., \& Ory, M. G. (2011). Successful aging and resilience: Applications for public health and health care. Dalam B. Resnick, L. P. Gwyther, \& K. A. Roberto (Eds.), Resilience in aging: Concepts, research, and outcomes (hlm. 15-30. New York, NY: Springer.

Junita, E. (2013). Hubungan umur ibu hamil dengan kejadian abortus di RSUD Rokan Hulu. Jurnal Maternity and Neonatal, 1(2), 67-74.

Karatas, Z., \& Cakar, F. S. (2011). Self-esteem and hopelessness, and resiliency: An exploratory study of adolescents in Turkey. International Education Studies, 4(4), 84-91. doi: 10.5539/ies.v4n4p84

Khairani, R., \& Putri, D. E. (2008). Kematangan emosi pada pria dan wanita yang menikah muda. Jurnal Psikologi, 1(2), 136-139.

Kim, T. H., Lee, S. M., Yu, K., Lee, S., \& Puig, A. (2005). Hope and the meaning of life as influences on Korean adolescents' resilience: implications for counselors. Asia Pacific Education Review, 6(2), 143-152.

Kirmani, M, N., Sharma, P., Anas, M., \& Sanam, R. (2015). Hope, resilience and subjective wellbeing among college going adolescent girls. International Journal of Humanities \& Social Science Studies, 2(1), 262-270.

Lentz, G. M., Lobo, R. A., Gershenson, D. M., \& Katz, V. L. (2012). Comprehensive gynecology (6th ed.). Philadephia, PA: Elsevier.

Malik, A. (2013). Efficacy, hope, optimism, and resilience at workplace - positive organizational behavior. International Journal of Scientific and Research Publication, 3(10), 1-4.

Mardiyanti, I. (2015). Kejadian keguguran ditinjau dari umur ibu di BPS Ita Ariani Wonoayu Sidoarjo. Jurnal Ilmiah Kesehatan, 8(2), 213-220.

Mednick, L., Cogen, F., Henderson, C., Rohrbeck, C. A., Kitessa, D., \& Streisand, R. (2007). Hope more, worry less: Hope as a potential resilience factor in mothers of very young children with type 1 diabetes. Children's Healthcare, 36(4), 385-396.

Nisfiannoor, M. (2009). Pendekatan statistika modern untuk ilmu sosial. Jakarta: Salemba Humanika. 
Oktan, V. (2012). Hope as a moderator in the development of psychological resilience. International Journal of Human Sciences, 9(2), 1691-1701.

Papalia, D. E., Feldman, R. D., \& Martorell, G. (2012). Experience human development (12th ed.). New York, NY: McGraw-Hill.

Pranata, S., \& Sadewo, F. S. (2012). Kejadian keguguran, kehamilan tidak direncanakan dan pengguguran di Indonesia. Buletin Penelitian Sistem Kesehatan, 15(2), 180-192.

Reivich, K., \& Shatté, A. (2002). The resilience factor: 7 essential skills for overcoming life's inevitable obstacles. New York, NY: Broadway.

Saifullah, M. (2011). Aborsi dan resikonya bagi perempuan (dalam pandangan hukum Islam). Jurnal Sosial Humaniora, 4(1), 13-25.

Santrock, J. W. (2012). Educational Psychology (5th ed.). New York, NY: McGraw-Hill.

Shetty, V. (2015). Resiliency, hope, and life satisfaction in midlife. IOSR Journal of Humanities and Social Science, 20(6), 29-32. doi: 10.9790/0837-20632932

Smith, B. W., Dalen, J., Wiggins, K., Tooley, E., Christopher, P., \& Bernard, J. (2008). The brief resilience scale: assessing the ability to bounce back. International Journal of Behavioral Medicine, 15(3), 194-200. doi: 10.1080/10705500802222972

Smith, B. W., Tooley, E. M., Christopher, P. J., \& Kay, V. S. (2010). Resilience as the ability to bounce back from stress: A neglected personal resource? The Journal of Positive Psychology, 5(3), 166-176. doi: 10.1080/17439760.2010.482186

Snyder, C. R. (1994). The psychology of hope: You can get there from here. New York, NY: Free Press.

Sugiyono. (2012). Metode penelitian kuantitatif, kualitatif, dan R\&D. Bandung: Alfabeta.

Wright, M. O., Masten, A. S., \& Narayan, A. J. (2014). Resilience processes in development: Four waves of research on positive adaptation in the context of adversity. Dalam S. Goldstein, \& R. B. Brooks (Eds), Handbook of resilience in children (hlm. 15-37). New York, NY: Springer. 